\title{
Stages of breast reconstruction and quality of life after breast cancer
}

\author{
Aline Fernanda Fontinele Murici ${ }^{1}$ (D), Ângela Ferreira Barros* (1)
}

\section{ABSTRACT}

Objective: To evaluate which stage of breast reconstruction promotes improved quality of life for women treated for breast cancer, and to verify the socioeconomic and clinical factors associated with better quality of life. Methods: A cross-sectional study was conducted with 70 women treated for breast cancer in the perioperative period of late breast reconstruction in the Federal District. To assess quality of life, the Functional Assessment of Cancer Therapy - Breast (FACT-B) instrument was used. Results: Half of the women were under 50 years old. Tumor removal surgery had occurred on average 5.4 years ago. Women with axillary dissection had greater impairment in the physical well-being domain $(p=0.001)$ and the breast cancer subscale $(p=0.016)$. Among women who had undergone surgery more than one year previously, there were higher domains of emotional $(p=0.006)$ and functional ( $p=0.003$ ) well-being. Women who underwent breast reconstruction had higher values in the social/family well-being $(p<0.001)$, emotional well-being $(p=0.001)$, functional well-being $(p=0.001)$, and breast cancer subscale $(p=0.005)$ domains; and on the FACT-B score $(p<0.001)$, right after the first stage. Conclusions: Breast reconstruction favored better quality of life from the first stage, suggesting that this therapeutic modality should be offered promptly, whenever possible, and guaranteed for all women treated for breast cancer.

KEYWORDS: breast neoplasms; mammaplasty; mastectomy; quality of life.

\section{INTRODUCTION}

In Brazil, breast cancer is the most common type of cancer among women, accounting for $29.5 \%$ of cases in 2018 , and excluding cases of non-melanoma skin cancer ${ }^{1}$. In most women, the diagnosis occurs in advanced stages ${ }^{2}$, which implies the need to use more aggressive treatments with a greater impact on the quality of life of women affected by the disease.

Surgical treatment with total or partial removal of breasts and axillary lymph nodes is an effective method to eradicate the tumor, however, it is a mutilating procedure, as it removes organs that are a symbol of femininity for women, and can provide a negative effect on their quality of life ${ }^{3}$.

To counteract these effects, breast reconstruction in Brazil has been increased by the Public Health System ${ }^{4}$, with the aim of improving the quality of life of women undergoing surgical treatment for breast cancer. As such, the goal is to establish body aesthetics and improve women's self-image by restoring the volume lost in their breast with cancer and recreating the symmetry with the contralateral breast ${ }^{3}$.
Some studies have found an association between breast reconstruction and better quality of life ${ }^{5}$, both for immediate and late reconstruction in prospective analysis ${ }^{6}$. On the other hand, breast reconstruction can occur at various times. Thus, the entire reconstruction process can take months or years, and it is not clear from studies that assess quality of life how each step interferes with quality of life?

Therefore, the objectives of this study are to assess which stage of breast reconstruction promotes an improvement in the quality of life of women treated for breast cancer and to verify the socioeconomic and clinical factors associated with better quality of life.

\section{METHODS}

An analytical and cross-sectional study was carried out using a quantitative approach, with women who underwent breast cancer treatment and who were undergoing perioperative breast reconstruction at the plastic surgery outpatient clinic of the 
Regional Hospital of Asa Norte, of the State Health Department of the Federal District (Secretaria de Estado de Saúde do Distrito Federal - SES/DF), Brasília, Federal District. This hospital is a reference in plastic surgery at the SES/DF.

These women were referred to this service by mastologists and/or oncologists after the surgical procedure for breast cancer removal and chemotherapy and/or radiotherapy treatments, as indicated for each case. Some still underwent hormone therapy, which did not prevent breast reconstruction. In addition, they presented no evidence of the disease and had good clinical conditions to either start the reconstruction or go through another stage of reconstruction, for those who had already undergone the first phase of immediate reconstruction.

Inclusion criteria were: having undergone surgical treatment for breast cancer, having physical and mental conditions that allowed them to communicate with the researcher and consent to participate in the research. The exclusion criteria were difficulties in communicating and not agreeing to participate in the research.

The data collection consisted of applying two questionnaires. The first addressed socioeconomic and clinical conditions. The second addressed quality of life through Functional Assessment of Cancer Therapy - Breast (FACT-B), version 4. It is a specific questionnaire for breast cancer patients. It is easy to administer and has been validated in Brazil, showing good internal consistency, high reliability and good reproducibility rates8.

Data collection was carried out from June to December 2015. Women were approached while they were waiting for care at the breast reconstruction plastic surgery outpatient clinic of the referred hospital. Those who underwent immediate reconstruction at the same time as tumor removal surgery were considered to have at least one reconstruction stage already performed.

The research was approved by the Research Ethics Committee of the Education and Research Foundation in Health Sciences of SES/DF (opinion no 1076842) with respect to Resolution nº 466/2012, of the National Health Council.

For data analysis, a descriptive analysis was initially performed, with measures of central tendency and dispersion for quantitative variables and percentage distribution for qualitative variables. Then, in the results of each domain and FACT-B scale, the Kolmogorov-Smirnov test was applied, which indicated the normal distribution of the sample in each of them, except in the emotional well-being domain. Thus, the Student's $t$ test was used to verify association with socioeconomic and clinical characteristics, except for this last domain, for which the Mann-Whitney U test was used. Statistical significance was set at $\mathrm{p}<0.05$. The analysis was performed using the Statistical Package for the Social Sciences (SPSS) software, version 20.0.

\section{RESULTS}

The sample consisted of 70 patients. The women had a average age of 51.8 years old, standard deviation (SD)=9.1, and the majority were between 40 and 49 years old. Half of the women were married (50\%), the average number of children they had was 2.4 ( $\mathrm{SD}=1.3$ ), the majority lived in the Federal District (75.7\%), in their own home (81.4\%), with an average of $3.2(\mathrm{SD}=1.1)$ residents in the home and an average family income of $\mathrm{R} \$ 2,492(\mathrm{SD}=2,183.5)$. Most self-declared themselves to be light-skinned black (57.1\%), had completed high school (40\%) and had been on sick leave due to the illness $(38.6 \%)$ (Table 1).

Regarding clinical data, non-conservative breast surgery was the most prevalent (81.4\%), as well as axillary dissection (67.1\%). The tumor removal surgery had occurred, on average, 5.4 years beforehand ( $\mathrm{SD}=4.9)$ (Table 2).

The participants were originally referred from tertiary hospitals (38.6\%), from the hospital where they awaited late breast reconstruction (31.4\%), from other public hospitals in the FD (22.9\%) or from hospitals in other states (7.1\%).

The functional well-being domain was the most compromised, with an average of $19.3(\mathrm{SD}=4.8)$. The breast cancer subscale was the most favorable, with a average of $24.8(\mathrm{SD}=6.3)$ (Table 3).

Tables 4 and 5 show the results of the association of clinical characteristics with the domains and scores of the FACT-B questionnaire.

Regarding the type of surgery (conservative or non-conservative), there was no statistically significant association with the domains and scores. In view of this result, we decided to analyze the other variables considering all the women in the sample, not excluding those who underwent conservative surgery.

Women who underwent axillary dissection had greater impairment in the physical well-being $(\mathrm{p}=0.001)$ and the breast cancer subscale $(\mathrm{p}=0.016)$ domains. The same could be observed in the scores, in which the women who underwent axillary dissection had lower values in the Trial Outcome Index (TOI), that is, in the sum of the following subscales: physical well-being, functional well-being and breast cancer $(\mathrm{p}=0.031)$.

Among women for whom more than one year of surgery had passed, there were greater domains of emotional $(\mathrm{p}=0.006)$ and functional well-being ( $\mathrm{p}=0.003)$. In the evaluation of the scores, no association of this variable was observed.

Women with at least one stage of breast reconstruction had higher values in the social/family well-being $(\mathrm{p}<0.001)$, emotional well-being ( $p=0.001)$, functional well-being $(\mathrm{p}=0.001)$ and breast cancer subscales $(\mathrm{p}=0.005)$. Similarly, an association between at least one stage of breast reconstruction and the FACT-B scores was observed, with higher averages: FACT-B TOI ( $\mathrm{p}=0.002)$, FACT-G $(\mathrm{p}<0.001)$, FACT-B Total $(\mathrm{p}<0.001)$.

Higher statistically significant averages of the domains and scores were found in women who had already undergone 
the first stage of breast reconstruction compared to those who had not undergone any stage, except in the physical wellbeing domain. No statistically significant differences were identified in the averages of the domains and scores beyond the first stage, as additional stages of breast reconstruction were performed.

Table 1. Distribution of socioeconomic and demographic characteristics of women in perioperative breast reconstruction in the plastic surgery outpatient clinic of Hospital Regional da Asa Norte (HRAN), Brasília, Federal District, between June and December 2015 ( $N=70$ ).

\begin{tabular}{|c|c|c|c|}
\hline Variable & Categories & $\mathbf{N}$ & $\%$ \\
\hline \multirow{4}{*}{ Age group } & Younger than 40 years old & 5 & 7.1 \\
\hline & Between 40 and 49 years old & 30 & 42.9 \\
\hline & Between 50 and 59 years old & 19 & 27.1 \\
\hline & 60 years old or older & 16 & 22.9 \\
\hline \multirow{2}{*}{ Residency } & Federal District & 53 & 75.7 \\
\hline & Outside the Federal District & 17 & 24.3 \\
\hline \multirow{2}{*}{ Skin color } & White & 21 & 30.0 \\
\hline & Dark-skinned or light-skinned black & 49 & 70.0 \\
\hline \multirow{2}{*}{ Marital status } & Married or common-law married & 35 & 50.0 \\
\hline & Single/separated/divorced/widowed & 35 & 50.0 \\
\hline \multirow{3}{*}{ Education level } & Completed elementary education & 29 & 41.4 \\
\hline & Completed high school education & 31 & 44.3 \\
\hline & Completed higher education & 10 & 14.3 \\
\hline \multirow{5}{*}{ Occupation } & Retired/Receives a pension & 15 & 21.4 \\
\hline & Housewife & 4 & 5.7 \\
\hline & Salaried or self-employed & 21 & 30.0 \\
\hline & Unemployed & 3 & 4.3 \\
\hline & On sick leave & 27 & 38.6 \\
\hline
\end{tabular}

Table 2. Distribution of clinical and surgical characteristics of women in perioperative breast reconstruction in the plastic surgery outpatient clinic of Hospital Regional da Asa Norte (HRAN), Brasília, Federal District, between June and December 2015 (N=70).

\begin{tabular}{|c|c|c|c|}
\hline Variable & Categories & $\mathbf{N}$ & $\%$ \\
\hline \multirow{2}{*}{ Surgery type } & Conservative & 13 & 18.6 \\
\hline & Not conservative & 57 & 81.4 \\
\hline \multirow{2}{*}{ Axillary dissection } & Yes & 47 & 67.1 \\
\hline & No & 23 & 32.9 \\
\hline \multirow{2}{*}{ Chemotherapy } & Yes & 55 & 78.6 \\
\hline & No & 15 & 21.4 \\
\hline \multirow{2}{*}{ Radiotherapy } & Yes & 52 & 74.3 \\
\hline & No & 18 & 25.7 \\
\hline \multirow{2}{*}{ Hormonal therapy } & Yes & 27 & 38.6 \\
\hline & No & 43 & 61.4 \\
\hline Time since tumor & Less than a year & 12 & 17.1 \\
\hline \multirow{2}{*}{ Removal surgery } & Between one and five years previously & 26 & 37.2 \\
\hline & Longer than five years previously & 32 & 45.7 \\
\hline \multirow{4}{*}{$\begin{array}{l}\text { Stage of breast } \\
\text { reconstruction }\end{array}$} & None & 27 & 38.6 \\
\hline & Stage 1 & 18 & 25.7 \\
\hline & Stage 2 & 09 & 12.9 \\
\hline & Further than stage 2 & 16 & 22.8 \\
\hline
\end{tabular}


Table 3. Distribution of the results of the domains and scores of the Functional Assessment of Cancer Therapy - Breast (FACT-B) instrument according to the responses of women in perioperative breast reconstruction in the plastic surgery outpatient clinic of Hospital Regional da Asa Norte (HRAN), Brasília, Federal District, between June and December 2015.

\begin{tabular}{|c|c|c|c|c|c|c|}
\hline & & Average & Median & $\begin{array}{l}\text { Standard } \\
\text { deviation }\end{array}$ & Minimum & Maximum \\
\hline \multirow{5}{*}{ Domains } & Physical wellbeing & 21.9 & 23.0 & 4.4 & 13.0 & 28.0 \\
\hline & Social/family well-being & 19.7 & 21.0 & 4.9 & 3.0 & 27.0 \\
\hline & Emotional well-Being & 20.0 & 21.0 & 3.6 & 7.0 & 24.0 \\
\hline & Functional well-being & 19.3 & 19.0 & 4.8 & 6.0 & 28.0 \\
\hline & Breast cancer subscale & 24.8 & 25.0 & 6.3 & 12.0 & 37.0 \\
\hline \multirow{3}{*}{ Scores } & FACT-B TOI & 66.0 & 66.0 & 12.6 & 38.0 & 93.0 \\
\hline & FACT-G TOTAL & 81.0 & 81.7 & 13.1 & 44.0 & 106.0 \\
\hline & FACT-B TOTAL & 105.7 & 106.5 & 17.6 & 56.0 & 143.0 \\
\hline
\end{tabular}

TOI: Trial Outcome Index; FACT-G: Functional Assessment of Cancer Therapy - General.

Table 4. Relationship between the domains of the Functional Assessment of Cancer Therapy - Breast (FACT-B) questionnaire with the variables referring to socioeconomic and clinical data. Brasília, Federal District, 2015.

\begin{tabular}{|c|c|c|c|c|c|}
\hline & $\begin{array}{l}\text { Physical } \\
\text { wellbeing }\end{array}$ & $\begin{array}{l}\text { Social/family } \\
\text { well-being }\end{array}$ & $\begin{array}{c}\text { Emotional Well- } \\
\text { Being }\end{array}$ & $\begin{array}{c}\text { Functional well- } \\
\text { being }\end{array}$ & $\begin{array}{l}\text { Breast cancer } \\
\text { subscale }\end{array}$ \\
\hline & Average (SD) & Average (SD) & Average (SD) & Average (SD) & Average (SD) \\
\hline Axillary dissection & $20.8(4.3)$ & $20.2(4.3)$ & $20.0(3.6)$ & $19.4(4.0)$ & $23.5(5.7)$ \\
\hline No axillary dissection & $24.3(3.9)$ & $18.8(5.9)$ & $19.9(3.6)$ & $19.0(6.1)$ & $27.3(6.6)$ \\
\hline p-value & $0.001^{*}$ & $0.291 *$ & $0.980 * *$ & $0.752^{*}$ & $0.016^{*}$ \\
\hline$\leq 1$ уеаг since surgery & $22.8(3.6)$ & $19.1(4.8)$ & $17.8(3.2)$ & $15.7(4.9)$ & $24.9( \pm 4.7)$ \\
\hline$>1$ year since surgery & $21.8(4.6)$ & $19.9(4.9)$ & $20.4(3.5)$ & $20.0(4.4)$ & $24.7(6.6)$ \\
\hline p-value & $0.494^{*}$ & $0.615^{*}$ & $0.006 * *$ & $0.003 *$ & $0.924 *$ \\
\hline Underwent reconstruction & $22.4(4.4)$ & $21.3(3.8)$ & $21.1(2.6)$ & $20.7(4.6)$ & $26.4(6.1)$ \\
\hline Did not undergo reconstruction & $21.2(4.6)$ & $17.1(5.3)$ & $18.1(4.1)$ & $16.9(4.2)$ & $22.1(5.6)$ \\
\hline p-value & $0.262 *$ & $<0.001 *$ & $0.001 * *$ & $0.001^{*}$ & $0.005^{*}$ \\
\hline No reconstruction stage & $21.2(4.6)$ & $17.1(5.3)$ & $18.1(4.1)$ & $16.9(4.2)$ & $22.1(5.6)$ \\
\hline 1 stage of reconstruction & $23.2(3.6)$ & $21.4(3.7)$ & $21.5(2.7)$ & $20.3(4.9)$ & $26.9(5.7)$ \\
\hline p-value & $0.129 *$ & $0.005^{*}$ & $0.004 * *$ & $0.019 *$ & $0.008^{*}$ \\
\hline
\end{tabular}

SD: standard deviation; * Student $t$ test; ** non-parametric test (Mann-Whitney U test).

Table 5. Relationship between the scores of the Functional Assessment of Cancer Therapy - Breast (FACT-B) questionnaire and the variables referring to socioeconomic and clinical data. Brasília, Federal District, 2015.

\begin{tabular}{|c|c|c|c|}
\hline & FACT-B TOI & FACT-G TOTAL SCORE & FACT-B TOTAL SCORE \\
\hline & Average (SD) & Average (SD) & Average (SD) \\
\hline Axillary dissection & $63.7(11.6)$ & $80.3(11.3)$ & $103.9(15.5)$ \\
\hline No axillary dissection & $70.6(13.6)$ & $82.3(16.3)$ & $109.6(21.1)$ \\
\hline p-value* & 0.031 & 0.567 & 0.200 \\
\hline$\leq 1$ year since surgery & $63.3(9.4)$ & $75.2(11.8)$ & $100.2(13.2)$ \\
\hline$\leq 1$ year since surgery & $66.5(13.2)$ & $82.2(13.1)$ & $106.9(18.2)$ \\
\hline p-value* & 0.432 & 0.095 & 0.228 \\
\hline Underwent reconstruction & $69.5(11.9)$ & $85.7(10.4)$ & $112.2(14.7)$ \\
\hline Did not undergo reconstruction & $60.3(11.7)$ & $73.4(13.4)$ & $95.5(17.2)$ \\
\hline p-value* & 0.002 & $<0.001$ & $<0.001$ \\
\hline No reconstruction stage & $60.3(11.7)$ & $73.4(13.4)$ & $95.5(17.2)$ \\
\hline 1 stage of reconstruction & $70.3(10.1)$ & $86.7(10.2)$ & $113.6(13.4)$ \\
\hline$p$-value* & 0.005 & 0.001 & 0.001 \\
\hline
\end{tabular}

TOI: Trial Outcome Index; SD: standard deviation; *Student $t$ test. 
There were no statistical associations between the domains and scores with the other variables in the socioeconomic and clinical questionnaire: age group, origin, skin color, marital status, education, occupation and types of treatment.

\section{DISCUSSION}

The women treated for breast cancer participating in the present study had a higher quality of life according to the domains and scores of the FACT-B instrument, when compared to a previous study $^{9}$, except in the social/family well-being domain. They presented a higher quality of life, mainly those who underwent breast reconstruction right after the first stage, corroborating the results of another study?

As for the time since the tumor removal surgery, many women in the present study had had this surgery performed more than five years before. This is partly due to the selection of women in the perioperative period of breast reconstruction. As such, the women were evaluated after the end of the most aggressive breast cancer treatments, were in good general condition and had no signs of recurrence. This condition in itself favors a better quality of life compared to patients in other phases of treatment.

In the present study, the surgical procedure for having removed the tumor over a year before showed a statistical association with greater emotional and functional well-being. In a French study, quality of life after breast cancer surgery took one year to return to the same preoperative level ${ }^{10}$.

Regarding where the referral came from of the women interviewed, approximately $70 \%$ of them came from the hospital itself or from tertiary care services. Thus, it is worth questioning whether breast reconstruction has been offered to patients treated at other health services in the Federal District or if there are difficulties in accessing the specialized breast reconstruction clinic. Results of a national study ${ }^{4}$ with data from the Public Health System indicate that, between 2008 and 2014, the number of breast reconstructions was still insufficient to meet the entire demand, when taking into account the number of mastectomies performed. Even so, there has been a significant increase in breast reconstructions over the years.

Thus, breast reconstruction has increasingly assumed a central role in the treatment of breast cancer. For women, reconstruction is understood as the effectiveness and success of breast cancer treatment, as it fills the gap left on their body and helps them to overcome the suffering triggered by the disease ${ }^{11}$.

Women undergoing breast reconstruction have a better quality of life in the psychological and social relations domains ${ }^{3}$. A similar result was observed in the present study, in which the women who underwent reconstruction presented higher averages in the social/family, emotional and functional domains, when compared to those who did not.
There was no influence of breast reconstruction from the point of view of physical well-being in the present study. This can be justified by the implications of the reconstruction itself, which involves extensive tissue manipulation, causing physical discomfort and mobility changes that can also be caused by sequelae resulting from breast removal surgery. Some authors also found no significant differences in quality of life related to physical aspects in women undergoing breast reconstruction ${ }^{3}$.

However, a significant association was found between axillary dissection and worse averages in the domains of physical well-being and breast cancer subscale, as well as in the TOI score, which is closely linked to physical aspects and breast cancer in the present study. This association probably occurs because of complications resulting from this procedure, which can cause pain, lymphedema, decreased arm mobility and muscle weakness. In a Chinese study, a worse average was also achieved in the breast cancer subscale in women who had undergone axillary dissection ${ }^{12}$.

Emotional function, which is considered to be a fundamental element of quality of life, showed a higher average in patients who had undergone breast reconstruction or at least the first stage, as observed in another study ${ }^{7}$. This reinforces the benefits of breast reconstruction. Another study showed better quality of life in women who underwent immediate breast reconstruction compared to those who underwent late reconstruction ${ }^{6}$.

Thus, breast reconstruction provided a better quality of life for women treated for breast cancer from the first stage, suggesting that this therapeutic modality should be offered more quickly and be guaranteed to all patients treated for this disease, in order to improve their quality of life more quickly.

A limitation of the study is the reduced sample size of women. More time for data collection was required to reach a greater number of women eligible to participate in the study.

Further studies on the quality of life of this population are suggested to support the strengthening of management strategies that increase material and human resources for more availability of breast reconstruction, especially at the same time as surgical treatment, when technical conditions exist.

\section{ACKNOWLEDGMENTS}

This work was carried out with support from the School of Health Sciences (Escola Superior em Ciências da Saúde - ESCS).

\section{AUTHORS' CONTRIBUTIONS}

A.M. and A.B.: Design, acquisition of funding, investigation, methodology, formal analysis, project administration, supervision, validation, visualization, writing — reviewing \& editing. 


\section{REFERENCES}

1. Instituto Nacional de Câncer José Alencar Gomes da Silva. Coordenação de Prevenção e Vigilância. Estimativa 2018: Incidência de Câncer no Brasil. Rio de Janeiro: INCA; 2017.

2. Abrahão KS, Bergmann A, Aguiar SS, Thuler LCS. Determinants of advanced stage presentation of breast cancer in 87,969 Brazilian women. Maturitas [Internet]. 2015 [accessed on Aug 29, 2018];82(4):365-70. Available at: https://www.sciencedirect. com/science/article/pii/S037851221530027X. http://doi. org/10.1016/j.maturitas.2015.07.021

3. Paredes CG, Pessoa SGP, Peixoto DTT, Amorim DN, Araújo JS, Barreto PRA. The impact of breast reconstruction on the quality oflife of patients after mastectomy at the Plastic Surgery Service of Walter Cantídio University Hospital. Rev Bras Cir Plást [Internet]. 2013 [accessed on Aug 2, 2019];28(1):100-4. Available at: http://www.scielo.br/pdf/rbcp/v28n1/en_17.pdf. https://doi.org/10.1590/S1983-51752013000100017

4. Freitas-Júnior R, Gagliato DM, Moura Filho JWC, Gouveia PA, Rahal RMS, Paulinelli RR, et al. Trends in breast cancer surgery at Brazil's public health system. J Surg Oncol [Internet]. 2017 [accessed on Aug 2, 2019];115(5):544-9. Available at: https:// onlinelibrary.wiley.com/doi/full/10.1002/jso.24572. https:// doi.org/10.1002/jso.24572

5. Fanakidou I, Zyga S, Alikari V, Tsironi M, Stathoulis J, Theofilou P. Mental health, loneliness, and illness perception outcomes in quality of life among young breast cancer patients after mastectomy: the role of breast reconstruction. Qual Life Res [Internet].2018 [accessed on Aug 2,2019];27(2):539-43. Available at: https://link.springer.com/article/10.1007\%2Fs11136-0171735-x. https://doi.org/10.1007/s11136-017-1735-x

6. Zhong T, Hu J, Bagher S, Vo A, O’Neill AC, Butler K, et al. A comparison of psychological response, body image, sexuality, and quality of life between immediate and delayed autologous tissue breast reconstruction: a prospective long-term outcome study. Plast Reconstr Surg [Internet]. 2016 [accessed on Aug 2, 2019];138(4):77280. Available at: https://insights.ovid.com/pubmed?pmid=27673514. https://doi.org/10.1097/PRS.0000000000002536
7. Teo I, Reece GP, Christie IC, Guindani M, Markey MK, Heinberg LJ, et al. Body image and quality of life of breast cancer patients: influence of timing and stage of breast reconstruction. Psychooncology [Internet]. 2016 [accessed on Aug 2, 2019];25(9):1106-12. Available at: https://onlinelibrary. wiley.com/doi/full/10.1002/pon.3952. https://doi.org/10.1002/ pon.3952

8. Michels FAZ, Latorre MRDO, Maciel MS. Validity and reliability of the FACT-B+4 quality of life questionnaire specific for breast cancer and comparison of IBCSG, EORTC-BR23 and FACT-B+4 questionnaires. Cad Saúde Colet. 2012;20(3):321-8.

9. Türk KE, Yılmaz M. The effect on quality of life and body image of mastectomy among breast cancer survivors. Eur J Breast Health [Internet]. 2018 [accessed on Aug 2, 2019];14(4):20510. Available at: https://www.ncbi.nlm.nih.gov/pmc/articles/ PMC6170016/pdf/ejbh-14-4-205.pdf. https://doi.org/10.5152/ ejbh.2018.3875

10. Dauplat J, Kwiatkowski F, Rouanet P, Delay E, Clough K, Verhaeghe JL, et al. Quality of life after mastectomy with or without immediate breast reconstruction. Br J Surg [Internet]. 2017 [accessed on Aug 2, 2019];104(9):1197-1206. Available at: https://onlinelibrary.wiley.com/doi/full/10.1002/bjs.10537. https://doi.org/10.1002/bjs.10537

11. Inocenti A, Santos MA, Loyola EAC, Magalhães PAP, Panobianco MS. Impact of the effects of the reconstructive surgery in the life of women with breast cancer. Texto Contexto Enferm [Internet]. 2016 [accessed on Aug 2, 2019];25(2):e4520014. Available at: http://www.scielo.br/pdf/ tce/v25n2/0104-0707-tce-25-02-2016004520014.pdf. http:// dx.doi.org/10.1590/0104-07072016004520014

12. Yeo W, Mo FK, Pang E, Suen JJ, Koh J, Yip CH, et al. Quality of life of young Chinese breast cancer patients after adjuvant chemotherapy. Cancer Manag Res [Internet]. 2018 [accessed on Aug 2, 2019];10:383-9. Available at: https://www.ncbi.nlm. nih.gov/pmc/articles/PMC5826245/pdf/cmar-10-383.pdf. https://dx.doi.org/10.2147\%2FCMAR.S149983 